\title{
O CONTEXTO DA CRIAÇÃO DE ESCRITÓRIOS DE PROJETOS NAS ÁREAS DE TI: DOIS ESTUDOS DE CASO
}

\author{
THE CONTEXT OF ESTABLISHING PROJECT MANAGEMENT \\ OFFICES IN THE IT AREA: TWO CASE STUDIES
}

\author{
Andrea Giovanni Spelta \\ Universidade Municipal de São Caetano do Sul, Brasil \\ Alberto Luiz Albertin \\ Fundação Getúlio Vargas-FGV EAESP, São Paulo, Brasil
}

\begin{abstract}
Completing strategic Information Technology (IT) projects as planned is certainly an important objective for large firms. One of the measures adopted to reach this goal systematically is to create a Project Management Office in the IT area (PMO-IT). However, many firms consider the possibility of creating a PMO-IT, but decide not to do it. This paper presents the results of an exploratory research about the contextual drivers that determine the decision to create PMO-Its. Through two case studies of large Brazilian firms - one that created the entity and another which believes does not need it -, the drivers of the decision to create or not to create a PMO-IT were identified, and it was possible to confirm some of the drivers mentioned in the literature. This paper increases the undertstanding about this topic, which is important in the Management Information Systems field, as well as indicates paths for future research.
\end{abstract}

Key-words: Project Management Offices, PMO, Project Management, Management Information Systems

\section{RESUMO}

Concluir projetos estratégicos da área de Tecnologia de Informação (TI) conforme planejado certamente é um importante objetivo para organizações de grande porte. Uma das medidas adotadas para alcançar de forma sistemática esse objetivo é criar um Escritório de Projetos na área de TI (EP-TI). Entretanto, muitas empresas consideram a possibilidade de criar um EP-TI, mas decidem não fazer isso. Este artigo apresenta os resultados de uma pesquisa exploratória

Recebido em/Manuscript first received: 14/02/2009 Aprovado em/Manuscript accepted: 27/07/2009 Endereço para correspondência/ Address for correspondence

Andrea Giovanni Spelta, Universidade Municipal de São Caetano do Sul, Professor de Administração de Sistemas de Informação da Universidade Municipal de São Caetano do Sul (USCS) E-mail: agspelta@hotmail.com

Alberto Luiz Albertin, FGV-EAESP, Professor Titular na FGV-EAESP - Informática e Métodos Quantitativos E-mail: albertin@fgv.br

ISSN online: 1807-1775

Publicado por/Published by: TECSI FEA USP - 2009 
sobre os direcionadores contextuais que determinam a decisão das empresas de criar EP-TIs. Através de dois estudos de caso em grandes empresas nacionais - uma que criou a entidade e outra que acredita não precisar dela -, foram identificados os direcionadores da decisão de criar ou não criar um EP-TI, tendo sido possível confirmar alguns dos direcionadores da decisão previstos na literatura. $\mathrm{O}$ artigo aumenta o entendimento sobre este tema que é importante dentro da Administração de Tecnologia de Informação, bem como indica caminhos para pesquisa futura.

Palavras-chave: Escritórios de Projetos, PMO, Gerenciamento de Projetos, Administração de Tecnologia de Informação

\section{INTRODUÇÃO}

Assistimos na última década ao aumento do interesse tanto da academia como de organizações empresariais pelas técnicas de gerenciamento de projetos. A existência de projetos em organizações e a necessidade de gerenciá-los certamente não são novas. No final do século XX, porém, devido a várias forças sociais -- tais como a globalização e o consequente acirramento da concorrência, ou a aceleração do ritmo da mudança nos negócios provocada pela tecnologia de informação e comunicação de dados (VERZUH, 2000), para citar apenas algumas dessas forças --, houve um enorme aumento na quantidade de projetos em execução nas organizações, bem como nas expectativas de conclusão destes projetos em prazos mais curtos e com custos menores, mas sem prejuízo da qualidade.

Nesse cenário, não é de surpreender que, desde meados da década de 1990 (DAI; WELLS, 2004), uma tendência começou a ganhar força no mundo corporativo: a criação de entidades organizacionais denominadas Escritórios de Projetos (EP) -- ou Project Management Offices (PMO), nome esse bastante popularizado no Brasil --, que centralizam assuntos relacionados ao gerenciamento dos projetos de uma organização. O conceito de ter um grupo de pessoas dedicado à gestão de projetos começou a emergir em organizações fora dos setores de engenharia e construção no final dos anos 1980 e início dos anos 1990 (ENGLUND; GRAHAN; DINSMORE, 2003). O movimento em direção ao estabelecimento de EP ganhou força em 1994 e as empresas de TI ou as áreas de TI das empresas foram proeminentes neste movimento (DAI; WELLS, 2004).

Esta pesquisa teve o objetivo de identificar os direcionadores da decisão de criar ou não criar um Escritório de Projetos na área de TI (EP-TI) através da exploração do contexto organizacional de duas empresas, uma com EP-TI e outra sem, ambas de grande porte, privadas e controladas por brasileiros. Assim, foram indagadas a estas empresas quais as razões que motivaram as decisões de criar e não criar um EP-TI, respectivamente. Talvez por ser um fenômeno relativamente recente, grande parte das proposições sobre a criação de EP encontradas na literatura carecem de suporte empírico sólido. Esta pesquisa oferece evidências confirmatórias dos direcionadores encontrados na literatura, contribuindo para o avanço na pesquisa sobre o tema EP.

Há duas razões para a importância de discussões sobre EP. A primeira, é que EP estão relacionados com a implementação de estratégias de negócio, pois é através de projetos que uma empresa implementa suas estratégias (ENGLUND; GRAHAN; DINSMORE, 2003). Embora o sucesso de um projeto não seja garantido pelo sucesso do gerenciamento do projeto, o sucesso do gerenciamento do projeto amplia as chances 
de sucesso do projeto (MUNNS; BJEIRNI, 1996), o que permite argumentar que o gerenciamento de projetos pode se tornar um ativo estratégico para competir (JUGDEV, 2004). Como veremos na revisão de literatura, EP frequentemente são criados visando aperfeiçoar o gerenciamento de projetos e diminuir o número de projetos problemáticos. Assim, um EP adquire importância estratégica, tornando relevante o estudo de sua criação. A segunda razão é que muitas empresas estão criando EP, logo o estudo deste fenômeno é interessante tanto para a prática como para a academia. Para prática, porque do estudo podem resultar recomendações sobre quando é oportuno criar EP. Para a academia, pela oportunidade de colocar em perspectiva esse fenômeno, entendendo seus direcionadores e permitindo o estabelecimento de teorias explicativas e preditivas.

\subsection{REVISÃO DA LITERATURA}

A revisão possui três seções. Na primeira, apresentamos a definição de EP adotada nesta pesquisa e as características dessa entidade. Na segunda, as motivações para a criação de EP. Na terceira, as motivações para não criar a entidade. Na terceira, fazemos uma síntese da literatura e apresentamos a questão de pesquisa.

\section{Escritórios de Projetos: conceituação e características}

EP são entidades organizacionais a quem são atribuídas diversas responsabilidades relacionadas a "...centralizar e coordenar o gerenciamento de projetos sob seu domínio” (PROJECT MANAGEMENT INSTITUTE, 2004, p. 369; Hobbs, Aubry, 2007, p. 74; Aubry, Hobbs, Thuillier, 2007, p. 331). Há autores que apresentam definições diferentes, mas em comum com a definição acima enfatizam a função de centralização exercida pelo EP no referente ao gerenciamento de projetos dentro das empresas. Rad (2001, p. PM.07.1) afirma que um EP provê “ um ponto focal para atividades de gerenciamento de projetos organizacionais”. Bernstein (2000, p. 4) sustenta que um EP é "uma camada formal e centralizada de controle entre a alta direção e a gestão de projetos”.

A literatura não acadêmica tradicionalmente caracteriza os EP em três diferentes níveis de acordo com seu posicionamento dentro da estrutura organizacional (ENGLUND; GRAHAN; DINSMORE, 2003; CRAWFORD, 2002). Esses níveis, seus nomes e características são apresentados a seguir: a) Nível 1 - Nível de projeto, isto é, o EP tem sob seu domínio apenas um projeto; b) Nível 2 - Nível funcional ou departamental, isto é, o EP tem sob seu domínio todos os projetos de uma unidade funcional, por exemplo, a área de TI da empresa; c) Nível 3 - Nível corporativo ou estratégico, isto é, o EP tem sob seu domínio todos os projetos de uma unidade de negócios, ou de todas as unidades de negócio de uma corporação. Esta literatura enfatiza que maiores benefícios podem ser obtidos para EP nível 3 e sugerem que as organizações evoluem do nível 1 para o nível 3. Nesta pesquisa, estudamos um EP estabelecido dentro da área de TI. Portanto, estamos tratando de EP nível 2, ou departamental/funcional

Hobbs e Aubry (2007) investigaram as características de EP no referente a nomes adotados, funções desempenhadas, idade, número dentro da organização, número de funcionários, autoridade de tomada de decisão, alocação de projetos e de gerentes de projetos. Os autores concluíram que essas características variam significativamente na 
população.

Com relação a nomes adotados para a entidade organizacional, os autores concluíram que, no Canadá e EUA, 59\% das empresas dão o nome Project Management Office à entidade, ao passo que $12 \%$ dão o nome Program Management Office. Embora semelhantes na aparência, entidades com estes nomes possivelmente possuem distintos níveis de autoridade e abrangência em suas organizações. Englund, Graham e Dinsmore (2003) sugerem pelo menos 20 possibilidades para os nomes atribuídos à entidade. Segundo esses autores, existe uma correlação entre as funções desempenhadas pela entidade e o nome adotado para ela. No Brasil, a tradução para o português do termo PMO sugerida pelo Project Management Institute (PMI) é Escritórios de Projetos (PROJECT MANAGEMENT INSTITUTE, 2004b), mas o uso do nome Project Management Office (PMO) parece ter se consagrado entre os profissionais da área (PROJECT MANAGEMENT INSTITUTE - Seção Rio de Janeiro, 2004/05/06). Neste trabalho, adotamos a tradução proposta pelo PMI.

Com relação às funções desempenhadas pelos EP, Hobbs e Aubry (2007) deram uma importante contribuição teórica ao campo ao reduzirem através de análise fatorial as enormes listas de funções de EP normalmente encontradas na literatura a cinco grupos de funções e três funções adicionais de importância média decrescente, conforme abaixo: a) monitorar e controlar o desempenho dos projetos; b) desenvolver competências e metodologias de gerenciamento de projetos; c) gerenciamento de múltiplos projetos; d) gerenciamento estratégico; e) aprendizado organizacional. As funções adicionais são: f) executar tarefas especializadas para gerentes de projetos (p.ex., preparar cronogramas); g) gerenciar interfaces com os clientes; h) recrutar, selecionar, avaliar e determinar salários para gerentes de projetos.

DeSouza e Evaristo (2006, p. 422) consideram que "o principal propósito de um EP é centralizar informação a fim de criar um repositório de conhecimentos”, que se assemelha ao grupo de funções indicado em (e) acima.

\section{Escritórios de Projetos: motivações para implementar}

Vários autores afirmam que a criação do EP vem ao encontro de uma demanda por maior excelência na execução de projetos. Englund, Grahan e Dinsmore (2003, p.19) consideram um grande fracasso em um projeto como um forte motivador para a idéia de criação do EP: “...no futuro quando as pessoas perguntarem a você: -- Por que criamos um EP ? -- relembre a elas que foi para evitar fracassos em grandes projetos.”. Crawford (2002) afirma que um EP cria uma estrutura de processos que soluciona os problemas relacionados com fracassos em projetos. Maximiano e Anselmo (2006), expondo um estudo de caso de criação de escritórios de projetos em uma empresa multinacional com subsidiária no Brasil, relatam que a implantação do EP surgiu como resposta a uma demanda por uma metodologia padronizada de gerenciamento de projetos, que se supõe visava desenvolver as competências da empresa em gerenciamento de projetos. Bernstein (2000) dá exemplos de problemas em gerenciamento de projetos que EP podem ajudar a identificar, reduzir e eliminar. Rad (2001) afirma que uma organização é uma boa candidata ao estabelecimento de um EP quando o número de projetos críticos com desempenho insatisfatório estiver acima de um limite ou quando os custos de projetos fora de controle são maiores do que a 
organização está disposta a suportar. Cleland e Ireland (2007) apresentam algumas justificativas para a criação de um EP, a saber, criar um ponto focal em ambiente de múltiplos projetos, evitar problemas nos projetos, comunicar a situação dos projetos às partes interessadas e estabelecer melhores práticas. Desouza e Evaristo (2006) afirmam que uma das principais causas de fracassos em projetos é uma pobre gestão de conhecimento em gerenciamento de projetos. Segundo os autores, o estabelecimento de EP é uma estratégia para resolver os problemas provocados por essa situação. Os autores afirmam ainda que a maioria dos EP recebe a responsabilidade de contribuir para o sucesso do gerenciamento de projetos da organização. Corroborando esses autores, Bernstein (2000) afirma que EP facilitam a transferência de conhecimento na organização. O referencial COBIT proposto pelo IT Governance Institute (2005) sugere que no estágio mais avançado do processo de gerenciamento de projetos de TI a organização estabelece um EP. Portanto, pode-se supor que organizações atentas às tendências de mercado sentem-se incentivadas a adotar as práticas de gerenciamento de projetos consideradas como as melhores de mercado.

Embora os autores acima não apresentem dados empíricos para sustentar suas afirmações, Dai e Wells (2004) apresentam dados empíricos sobre os motivos para a criação de EP que substancialmente corroboram a visão dos autores acima. Os principais motivadores em ordem de importância são: a) aperfeiçoar todos os elementos do gerenciamento de projetos para reduzir o número de projetos com problemas; b) alcançar um uso mais eficiente de recursos humanos e de outros tipos em ambiente de múltiplos projetos; c) melhorar a qualidade e satisfação do cliente; d) incorporar gerenciamento de projetos nas metas estratégicas e desenvolver vantagens competitivas. Outros motivadores foram apresentados, mas em nosso entender são variações dos mencionados acima.

O Quadro 1 resume a discussão acima, expondo os motivadores encontrados na revisão da literatura para criar um EP, bem como seus respectivos autores.

\begin{tabular}{|l|l|}
\hline \multicolumn{1}{|c|}{ Motivador } & Autores \\
\hline $\begin{array}{l}\text { Aperfeiçoar o gerenciamento de projetos e } \\
\text { reduzir o número de projetos problemáticos }\end{array}$ & - Bernstein (2000) \\
& - Cleland e Ireland (2007) \\
& - Crawford (2002) \\
& - Dai e Wells (2004) \\
& - Desouza e Evaristo (2006) \\
& - Englund, Grahan e Dinsmore \\
& (2003) \\
& - Maximiano e Anselmo (2006) \\
& - Rad (2001) \\
\hline $\begin{array}{l}\text { Usar recursos de modo mais eficiente em } \\
\text { ambiente de múltiplos projetos }\end{array}$ & - Cleland e Ireland (2007) \\
\hline Melhorar a qualidade e satisfação do cliente & Dai e Wells (2004) \\
\hline $\begin{array}{l}\text { Há necessidade de implementar projetos } \\
\text { estratégicos }\end{array}$ & - Bernstein (2000) \\
\hline $\begin{array}{l}\text { Facilitar a transferência de conhecimento sobre } \\
\text { gerenciamento de projetos na organização }\end{array}$ & - Block e Frame (1998) \\
\hline
\end{tabular}




\begin{tabular}{|l|l|}
\hline \multicolumn{1}{|c|}{ Motivador } & Autores \\
\hline $\begin{array}{l}\text { Atenção às práticas de gerenciamento de } \\
\text { projetos consideradas como as melhores pelo } \\
\text { mercado }\end{array}$ & - IT Governance Institute (2005) \\
\hline $\begin{array}{l}\text { Melhorar o controle e a comunicação sobre a } \\
\text { situação dos projetos }\end{array}$ & $\begin{array}{l}\text { - Cleland e Ireland (2007) } \\
\text { - Rad (2001) }\end{array}$ \\
\hline
\end{tabular}

Quadro 1: Resumo dos motivadores para estabelecer um EP.

\section{Escritórios de Projetos: motivações para não implementar}

Embora pareça óbvio que a criação de uma entidade destinada a promover o sucesso do gerenciamento de projetos na organização resulte em uma melhoria na taxa de sucesso dos projetos, as pesquisas sobre o tema apresentam resultados contraditórios e não dão sustentação inquestionável a essa premissa.

Dai e Wells (2004) concluíram que organizações com EP não mostram melhor desempenho nos projetos do que organizações sem EP. Contudo, os autores afirmam que as organizações com EP fazem mais do que as sem EP em termos de promover alguns fatores críticos que são correlacionados positivamente a um melhor desempenho nos projetos, tais como padrões e métodos de gerenciamento de projetos, arquivos com histórico de projetos, treinamento e aconselhamento de gerentes de projetos. Comentando estes resultados, Englund, Grahan e Dinsmore (2003) sustentam que as organizações deveriam enfocar a promoção desses fatores críticos de sucesso, devendo estabelecer um EP somente quando experimentassem dificuldade em promover estes fatores sem uma entidade organizacional dedicada a esta promoção.

Milosevic e Patanakul (2005) estudaram o impacto de diversas variáveis sobre o grau de sucesso dos projetos e concluíram que o uso de processos padronizados de gerenciamento de projetos está correlacionado positivamente com um maior sucesso nos projetos. Entretanto, a variável mais diretamente relacionada com EP (Organização) não apresentou correlação estatisticamente significativa com o sucesso dos projetos, o que o confirma os resultados obtidos por Dai e Wells (2004), citados anteriormente.

Jiang, Klein e Pick (2003) estudaram o impacto do ambiente organizacional sobre a performance de equipes de projetos. Os autores definiram a variável formalização como o grau com que a organização confia em regras e procedimentos formais. É lícito afirmar que esta variável está correlacionada positivamente com a existência de EP, pois EP usualmente atuam no desenvolvimento de metodologias de gerenciamento de projetos (HOBBS; AUBRY, 2007), o que leva a um maior grau de formalização dentro da organização. Entretanto, a pesquisa não encontrou evidências de correlação positiva entre a variável formalização e o sucesso em projetos.

Englund, Grahan e Dinsmore (2003) relatam que em um seminário sobre EP para profissionais do gerenciamento de projetos foram relacionadas 13 razões para não implementar um EP, conforme segue: a) não há provas concretas de que aprimora o sucesso dos projetos; b) concentra poder em partes da organização; c) dificulta as iniciativas dos gerentes de projeto; d) aumenta o custo fixo, portanto pode não justificar o investimento; e) estimula a burocracia; f) torna a responsabilidade de gerentes de projetos mais difusa; g) diluí a habilidade dos gerentes de projetos de dirigir as 
atividades; h) desvia bons funcionários do gerenciamento de projetos; i) pode multiplicar os erros; j) pode desviar a atenção da entrega dos projetos; $k$ ) tende a ser dirigido por processos, não por projetos; l) cria ressentimento entre os gerentes de projetos; m) estimula lutas de poder dentro da organização. Os autores argumentam, ainda, que há situações em que é melhor não insistir com a criação de EP:

Se, por exemplo, as pessoas estão treinadas e motivadas, existem metodologias, e ferramentas, software e hardware estão disponíveis e uma atmosfera saudável, sinérgica e produtiva existir -, então pode não haver necessidade de um EP. Ou, se a empresa for prioritariamente orientada a processos e opere em um ambiente estável e sem mudanças, um EP seria um luxo desnecessário (ENGLUND, GRAHAN, DINSMORE, 2003, p.59, tradução nossa).

Confirmando o item e) da lista acima, Bernstein (2000, p. 4) sustenta que quando "as pessoas pensam em implementar um EP, usualmente elas pensam em burocracia, papelada e custos mais altos".

Portanto, a literatura apresenta boas razões para desestimular uma organização a pensar em criar um EP. O 2 resume a discussão acima, expondo os motivadores encontrados na revisão da literatura para não criar o EP, bem como seus respectivos autores.

\begin{tabular}{|l|l|}
\hline Motivador & Autores \\
\hline $\begin{array}{l}\text { Não há provas de que melhora o desempenho } \\
\text { dos projetos }\end{array}$ & $\begin{array}{l}\text { - Dai e Wells (2004) } \\
\text { - Milosevic e Patanakul (2005) } \\
\text { - Jiang, Klein e Pick (2003) } \\
\text { - Englund, Grahan e Dinsmore (2003) }\end{array}$ \\
\hline $\begin{array}{l}\text { Aumenta o custo fixo e pode não } \\
\text { proporcionar benefícios que justificam este } \\
\text { aumento }\end{array}$ & $\begin{array}{l}\text { - Bernstein (2000) } \\
\text { - Englund, Grahan e Dinsmore (2003) }\end{array}$ \\
\hline Aumenta a burocracia & $\begin{array}{l}\text { - Englund, Grahan e Dinsmore (2003) } \\
\text { - Bernstein (2000) }\end{array}$ \\
\hline Cria conflitos entre setores da organização & Englund, Grahan e Dinsmore (2003) \\
\hline $\begin{array}{l}\text { Surgem conflitos e ressentimentos com os } \\
\text { gerentes de projetos }\end{array}$ & Englund, Grahan e Dinsmore (2003) \\
\hline $\begin{array}{l}\text { Perda de talentos para o gerenciamento de } \\
\text { projetos }\end{array}$ & Englund, Grahan e Dinsmore (2003) \\
\hline $\begin{array}{l}\text { O ambiente é estável, sem importantes } \\
\text { projetos a implementar }\end{array}$ & Englund, Grahan e Dinsmore (2003) \\
\hline $\begin{array}{l}\text { Os métodos de gerenciamento de projetos e } \\
\text { os resultados obtidos são satisfatórios }\end{array}$ & Englund, Grahan e Dinsmore (2003) \\
\hline
\end{tabular}

Quadro 2: Resumo dos motivadores para não estabelecer um EP. 


\section{Síntese da literatura e questão de pesquisa}

Embora existam importantes pesquisas acadêmicas sobre as características e os resultados obtidos por EP, apenas Dai e Wells (2004) apresentam resultados empíricos sobre as razões para a criação de EP. Porém, os autores não fazem referência às razões para não criar um EP e não investigam de forma aprofundada o contexto que gerou a decisão de criação de EP, pois abordam o tema EP de forma mais ampla. Ademais, as pesquisas realizadas sobre EP até hoje não enfocaram nem um tipo específico de organização, nem uma área em particular das organizações, o que gera uma variabilidade muito grande nos resultados ((HOBBS; AUBRY, 2007), dificultando sua interpretação. Para superar esta dificuldade, nessa pesquisa, enfoca-se a área de TI de duas grandes empresas privadas, nacionais, não orientadas a projetos. Acredita-se que a importância das atividades de gerenciamento de projetos dentro da Administração de TI justifica um estudo enfocando a criação de EP na área de TI.

Assim, pretende-se aprofundar a compreensão sobre o fenômeno de criação de EP através da colocação da seguinte questão de pesquisa: qual o contexto organizacional que leva uma empresa privada, nacional, não orientada a projetos a tomar a decisão de criar ou de não criar um EP na área de TI ?

\section{METODOLOGIA}

Nesta pesquisa explora-se o contexto organizacional que direciona a decisão sobre o estabelecimento ou não de EP na área de TI (EP-TI). Através da comparação das razões que levaram uma empresa a criar um EP-TI com as razões de outra empresa que pensa não precisar da entidade, acredita-se poder aumentar o entendimento sobre 0 fenômeno de criação de EP-TI. O método do estudo de caso é indicado quando se deseja fazer uma "investigação holística e aprofundada" (DUBÈ; PARRÈ, 2003) de um fenômeno. Assim, ele foi considerado apropriado para os objetivos da pesquisa. Para garantir uma aplicação rigorosa do método, seguimos as recomendações sugeridas por Dubé e Parrè (2003) e por Eisenhardt (1989).

Há interesse em abordar a questão de pesquisa em empresas que atendam os seguintes critérios: a) privada; b) controlada por brasileiros; c) de grande porte; d) não orientada a projetos. Empresas orientadas a projetos, tais como empresas de engenharia e consultoria, foram excluídas porque se considerou que a criação de EP nestas empresas é um fenômeno de menor interesse, por ser menos controverso. As duas empresas estudadas foram escolhidas devido à facilidade de acesso aos seus executivos.

O método de coleta de dados utilizado foi a condução de entrevistas com pessoas familiarizadas com as decisões da empresa sobre as práticas adotadas em gerenciamento de projetos na área de TI. Na empresa com EP-TI, foram entrevistados o diretor de TI, o responsável pela área de gerenciamento de projetos e o responsável pelo PMO. Na empresa sem EP-TI, os responsáveis pelas áreas de Governança de TI, de Desenvolvimento de Sistemas e de Infra-estrutura. Foram entrevistadas várias pessoas em cada empresa com o intuito de obter triangulação na coleta de dados.

Um protocolo para as entrevistas foi preparado e enviado aos entrevistados 
previamente. Algumas das questões eram abertas, outras no formato de múltipla escolha. Tinham-se dois propósitos com as questões. Primeiro, obter um quadro claro do contexto do departamento de TI, do EP-TI e das práticas de gerenciamento de projetos adotadas. Segundo, entender as motivações para o estabelecimento do EP-TI, ou por outro lado, entender porque a empresa considerava inoportuno criar a entidade. Todas as entrevistas foram gravadas, transcritas, sintetizadas e enviadas aos entrevistados para validação. Ao todo, obteve-se cerca de 4h de gravação.

Após validação, as transcrições das entrevistas foram analisadas usando técnicas de análise de conteúdo, conforme orientação oferecida por Trochim e Donnelly (2007). Basicamente, procurou-se ao longo do texto os trechos em que os entrevistados explicam os motivos para a decisão sobre a criação ou não do EP-TI, bem como o que se esperava como resultado desta decisão. Posteriormente, estes trechos foram categorizados buscando uma síntese.

\section{DESCRIÇÃO DOS CASOS}

\section{Empresa com EP-TI}

A empresa estudada atua no setor industrial, tem operações no exterior, faturou cerca de US\$ 4,4 bilhões em 2006 e conta com cerca de 19.000 funcionários, dos quais aproximadamente 220 atuam na área de TI. Cerca de 22 projetos encontram-se em andamento simultaneamente na área de TI e o percentual de projetos concluídos dentro do prazo, custo e com satisfação dos clientes foi de $67 \%$ em 2006. Será visto que esta empresa vem experimentando diferentes abordagens para aperfeiçoar suas competências em gerenciamento de projetos na área de TI. A principal razão por trás destas iniciativas é o baixo nível de satisfação tanto entre os clientes internos como na direção da empresa com a capacidade da área de TI de entregar projetos dentro do prazo, dentro do custo e com a satisfação dos clientes.

\section{Visão geral do EP-TI}

A estrutura da área de TI da empresa fora adotada pouco antes da realização das entrevistas. No contexto do gerenciamento de projetos, ela é uma evolução da estrutura anterior, que já contava com uma área desempenhando funções típicas de um EP-TI, denominada Gerência de Projetos, onde atuavam um líder e nove gerentes de projetos, encarregados de executar os projetos. Na nova estrutura, foi mantida a área de Gerenciamento de Projetos e foi criada uma nova área denominada PMO. Portanto, é lícito afirmar que a empresa conta com dois EP-TI.

O PMO conta com seis funcionários (cinco efetivos e um estagiário), não tem nenhuma autoridade de tomada de decisão sobre o andamento dos projetos, mas acompanha sua execução, sendo co-responsável pelos resultados. Se o PMO perceber que o projeto tem problemas, cabe a ele aconselhar o gerente de projeto e também sinalizar a existência desses problemas para a direção de TI. Portanto, nem projetos, nem gerentes de projetos estão alocados ao PMO. A função primordial do PMO consistiria em avaliar as demandas recebidas pelas áreas de negócios, validá-las e entregá-las à Gerência de Projetos apenas quando tivessem um grau suficiente de detalhamento e clareza, cabendo então à Gerência de Projetos a execução dos projetos 
dentro das metas de prazo, custo e qualidade. Ademais, cabe ao PMO dar visibilidade à carteira de projetos TI da empresa de uma forma padronizada, avaliar carga e capacidade de execução de projetos em TI e aplicar critérios de priorização de projetos. Portanto, o PMO enfocaria a gestão do portfolio, papel esse que nunca foi desempenhado pela área de Gerenciamento de Projetos.

\section{Razões para a criação do EP-TI}

Vamos inicialmente expor o histórico do desenvolvimento das competências em gerenciamento de projetos nesta empresa, pois ele ajuda a iluminar as motivações para a criação dos EP-TIs. Em seguida, abordamos diretamente as razões para a criação.

\section{$\underline{\text { Histórico }}$}

Em 2000, houve uma primeira iniciativa de criação de um EP-TI, mas foi abandonada em 2001, porque não deu bons resultados. A causa do fracasso é que não havia gerentes de projetos. Eram os analistas, com responsabilidades na produção e suporte, que gerenciavam os projetos.

Em 2003, foram retomados os esforços para desenvolver as competências organizacionais da área de TI em gerenciamento de projetos. Dentro da área de Sistemas e Aplicativos, começou a ser definido um profissional para gerenciar projetos. Esse profissional tinha dois papéis: o de gerente de projetos e o do analista de sistemas. Em função da percepção de que o papel do gerente de projetos ficava em segundo plano toda a vez que o analista de sistemas era chamado a dar suporte aos sistemas operacionais do dia-a-dia, em outubro de2005 foi montada uma estrutura dedicada ao gerenciamento de projetos. Criou-se uma Gerência de Projetos e nove funcionários foram alocados à área para atuarem exclusivamente como Gerentes de Projetos. Procurou-se desenvolver de forma mais consistente e intensa as competências em gerenciamento de projetos desses funcionários, criando métricas para medir a efetividade da área de gerenciamento de projetos e adotando ferramentas para uma melhor gestão dos projetos. Enquanto em 2003, a gestão de projetos enfocava escopo e prazo, em 2005, passou-se a considerar também custo, risco e comunicação, isto é, foi abrangido um número maior de disciplinas do modelo PMI (2004a) para gestão de projetos. Embora a área não fosse chamada de EP, na visão da responsável, a área desempenhava papéis normalmente atribuídos a um EP. Por exemplo, desenvolver uma metodologia padronizada para a gestão de projetos, bem como estabelecer métricas para acompanhar a efetividade da gestão de projetos de TI na empresa.

O foco do trabalho realizado a partir de 2005 foi ganhar qualidade na gestão dos projetos e melhorar a efetividade das entregas dos projetos, com pouca ênfase em melhorar a informação para a direção sobre a carteira de projetos da empresa. Houve, então, um importante aumento na taxa de projetos concluídos no prazo e no custo (de $30 \%$ em 2005 para 67\% em 2007). Uma das razões para isso está no fato de que até 2005 os gerentes de projetos não estavam dedicados exclusivamente a gerenciar projetos (cabe destacar que a formação do profissional de gerenciamento de projetos dentro de TI foi lenta; progressivamente, os antigos analistas de sistemas foram perdendo suas antigas responsabilidades em análise de sistemas e suporte a sistemas de produção, e foram passando a exercer exclusivamente as funções de gerente de 
projetos). Outra razão importante é que a metodologia de gestão de projetos usada pela empresa foi definida pelos próprios gerentes de projetos. Houve um forte investimento da Diretoria de TI neste sentido. Durante 10 meses, todas as sextas-feiras eram reservadas a reuniões em que os gerentes de projeto discutiam propostas elaboradas por eles próprios sobre os padrões e a metodologia de gestão de projetos a ser adotada. Naturalmente, os gerentes de projeto sentem-se mais inclinados a utilizar uma metodologia que eles ajudaram a construir. Essa melhoria na entrega dos projetos serviu para mostrar à direção que o caminho estava certo, isso é, que gestão de projetos agrega valor. Porém, era preciso ter pessoas dedicadas a gerenciar projetos; e também uma estrutura voltada a aprimorar a gestão de projetos na empresa.

Em 2005, foi criada ainda uma entidade de suporte dentro de um projeto ERP (Enterprise Resource Planning) que apresentava problemas. Essa entidade foi chamada de PMO, mas ela desempenhava apenas um papel de apoio ao planejamento e controle de um projeto estratégico, mas problemático. Como o foco deste PMO era exclusivamente este projeto, ele foi extinto com a conclusão do projeto. Cumpre destacar que, segundo o diretor de TI, a experiência com o EP nível 1 serviu para reforçar a determinação de criar um EP nível 2, em cujo domínio encontram-se todos os projetos de TI.

\section{$\underline{\text { Razões }}$}

Segundo a gerente da área de projetos (na estrutura de 2005), a criação do PMO em 2007 é mais um estágio em um processo de valorização do gerenciamento de projetos em TI. Antigamente, a área de TI se perdia no escopo no prazo e no custo, e tinha que se explicar com as áreas de negócios, quase que se desculpar. Graças ao trabalho do setor de Gerenciamento de Projetos, isso mudou. Existem fatos registrados sobre a condução do projeto e sabe-se explicar muito bem tanto o sucesso como o insucesso. Portanto, a maior razão para a criação dos EP-TIs é agregar valor garantindo a entrega dos projetos de TI. A entrevistada enfatizou que nas discussões sobre a nova estrutura de TI, em 2007, não foi mais questionado porque era preciso ter um grupo dedicado ao gerenciamento de projetos, ao passo que, em 2005, quando a área de Gerenciamento de Projetos foi criada, isso era muito questionado

Segundo o diretor de TI (por simplicidade referido doravante como CIO), muito embora existisse um contexto de transformação organizacional no momento da criação do PMO, não é este contexto que motivou sua criação. A idéia de criar o PMO teve início em 2005, com a criação da entidade mencionada anteriormente que se dedicava exclusivamente ao projeto ERP. Naquele momento, pensou-se em estender o conceito a todos os projetos de TI, caso a experiência desse bons resultados. A reestruturação organizacional ajudou a concretizar este plano. Cabe destacar que a criação do PMO foi bastante questionada pela alta direção da empresa, que argumentava se havia de necessidade de criar uma área de planejamento em TI, uma vez que já existia uma área de planejamento em nível corporativo. A justificativa do CIO para a criação da área é que ela iria permitir rastrear a situação de cada projeto, aumentando as chances de que projetos fossem concluídos no prazo, custo e escopo previstos.

O Quadro 3 resume dados sobre a satisfação de usuários, clientes e da direção com o gerenciamento de projetos na empresa no momento da criação dos EP-TIs. A escala de satisfação varia de nenhuma a muita, passando por pouca, razoável e 
considerável. Vemos que, em 2005, na criação da área de Gerência de Projetos, usuários e clientes tinham pouca satisfação no referente à performance de TI no atendimento a demandas (prazo e qualidade). Por sua vez, a direção de TI não estava satisfeita com aspectos da metodologia de gerenciamento de projetos adotada, nem com o andamento dos projetos. Já em 2007, na criação do PMO, a avaliação de usuários, clientes e executivos havia melhorado em todos os aspectos na opinião do líder da área de Gerência de Projetos, mas não na opinião do CIO.

\begin{tabular}{|c|c|c|}
\hline & $\begin{array}{l}\text { Criação Gerên } \\
\text { Projetos (20 }\end{array}$ & $\begin{array}{r}\text { Criaçã } \\
(20\end{array}$ \\
\hline $\begin{array}{l}\text { Grau de satisfação de } \\
\text { usuários e clientes com } \\
\text { relação à performance de } \\
\text { TI no atendimento a } \\
\text { demandas }\end{array}$ & $\begin{array}{l}\text { Líder - pouca } \\
\text { CIO - há percepção de que } \\
\text { prazos e custos não são } \\
\text { cumpridos }\end{array}$ & $\begin{array}{l}\text { Líder - considerável } \\
\text { CIO - há percepção de que } \\
\text { prazos e custos não são } \\
\text { cumpridos }\end{array}$ \\
\hline $\begin{array}{l}\text { Grau de satisfação de } \\
\text { executivos com relação } \\
\text { ao andamento dos } \\
\text { projetos e controle do } \\
\text { portfólio }\end{array}$ & $\begin{array}{l}\text { Líder - nenhuma } \\
\text { CIO - há percepção de que } \\
\text { prazos e custos não são } \\
\text { cumpridos, mas não há } \\
\text { queixas com relação à } \\
\text { visibilidade da carteira }\end{array}$ & $\begin{array}{l}\text { Líder - razoável } \\
\text { CIO - há percepção de que } \\
\text { prazos e custos não são } \\
\text { cumpridos, mas não há } \\
\text { queixas com relação à } \\
\text { visibilidade da carteira }\end{array}$ \\
\hline $\begin{array}{l}\text { Grau de satisfação da } \\
\text { direção de TI com a } \\
\text { metodologia de gerência } \\
\text { de projetos existente }\end{array}$ & $\begin{array}{l}\text { Líder - nenhuma } \\
\text { CIO - nenhuma } \\
\text { estabelecimento } \\
\text { requisitos }\end{array}$ & $\begin{array}{l}\text { Líder - considerável } \\
\text { CIO - nenhuma } \\
\text { estabelecimento } \\
\text { requisitos }\end{array}$ \\
\hline
\end{tabular}

Quadro 3: Satisfação com aspectos do gerenciamento de projetos na empresa com EPTI.

Percebe-se que a avaliação do CIO é mais negativa do que a da líder com relação à situação em 2007, o que, talvez, possa ser explicado pelo fato de que a líder da área de Gerência de Projetos estava avaliando o próprio trabalho. No referente à visibilidade da carteira, entretanto, a situação se inverte, e o CIO afirma que TI “...tem o melhor nível de visibilidade da empresa, a gente tem tudo bem estruturado...”, ao passo que a líder da área de Gerência de Projetos considera que há apenas satisfação razoável com a visibilidade. Tendo em vista que a líder de projetos não declarou que o nível de satisfação com a visibilidade foi um motivador para a criação do PMO, esta diferença de opiniões não é relevante para este estudo. Ou seja, não vamos considerar a insatisfação com a visibilidade como um motivador.

Abaixo são sintetizados os motivadores para a decisão de criar um EP-TI conforme opinião dos entrevistados, com reprodução das passagens das entrevistas que evidenciam a presença destes motivadores: 
a) Insatisfação com a metodologia de gerenciamento de projetos no referente ao estabelecimento de requisitos

Pesquisador: "vamos passar para a avaliação da metodologia de gerência de projetos existentes na época, aí a gente pode dizer de 2005 e de 2007, como você estava?” Líder Gerência de Projetos: “Antes [2005] era insatisfatória, cada um conduzia como podia, eu acho que a metodologia hoje [2007]...ela é bastante satisfatória, o que falta ainda é experiência...o problema ainda está antes, ainda chega muito ruim a demanda. Eu não sei se é possível ela chegar melhor, essa é uma dúvida... se tem uma coisa que o PMO pode ajudar muito o gerente de projeto é não fazer a pergunta para o gerente de projeto, é fazer para o analista de negócios [área de Processos, que define demanda com clientes]...”

Pesquisador: "Como você avalia a metodologia que você tinha em 2005 e a que você tem já hoje, enfim, você espera que o seu PMO trabalhe forte em cima disso?” CIO: “O grande ganho que a gente vai ter é no estabelecimento dos requisitos, é na disciplina de estabelecer os requisitos, de conseguir conscientizar a área usuária da importância disso.”

b) Insatisfação com a capacidade de TI de entregar projetos dentro do prazo, custo e com a qualidade esperada.

Pesquisador: "O que eu queria passar com você é esse ponto, razões que justificaram a criação do escritório de projetos...”. Líder Gerência de Projetos: “...porque a gente se perdia no escopo, no prazo e no custo e a gente explicava, mas não justificava, aliás a gente se desculpava o tempo todo com o usuário... antes [2005] a gente se perdia, a gente não sabia se o problema tinha sido de infra, se tinha sido... estava na cabeça das pessoas, ... mas não existia um processo onde aquilo ficava claro...o mais importante [era] agregar valor e entregar, garantir a entrega."

Pesquisador: "no momento em que você estava criando esse PMO, tem dois momentos ... vamos nesses dois momentos, 2005 e 2007, qual é o grau de satisfação dos seus usuários, dos seus clientes sobre performance de TI no atendimento à demandas, qualidade e prazo? CIO: “...existe uma percepção de que os prazos não são cumpridos e os custos também não, ainda existia em 2005 e ainda existe hoje.”

Pesquisador: "E com relação aos executivos, a percepção deles com relação também a esse atendimento? " CIO: “Também, também, isso eu quero mudar, é custo, na TI é custo e é complexo, não cumpre os prazos.”

Pesquisador: "O que você sente como mais importante para você, enfim, quando te perguntarem, isso aí [PMO-2007] realmente vai gerar custo fixo para você, e aí a sua liderança vai dizer, mais custo fixo? Como é que você vai defender [o PMO-2007] ?” CIO: “ Como eu defendo isso, eu consigo rastrear e garantir, ter melhor garantia de que o projeto vai ser cumprido no prazo, no escopo e no custo...”

\subsection{Empresa sem EP-TI}

Esta empresa atua no setor de serviços financeiros e é uma das maiores 
corporações brasileiras. A estrutura da área de TI é bastante complexa. Não existe uma única área centralizando todos os setores de TI, mas existe uma área que reúne os principais setores de TI, que incluem a infra-estrutura principal de TI e o desenvolvimento dos sistemas centrais para o negócio. Essa área conta com cerca de 3.000 funcionários em tempo integral, sendo cerca de 2.000 voltados ao desenvolvimento de sistemas e 1.000 ligados à infra-estrutura. Embora invista pesadamente em TI, contando com cerca de 1.500 projetos de TI em andamento simultaneamente somente em desenvolvimento de sistemas, essa área não possui EP-TI. Como se verá, a principal justificativa para essa situação é que a direção da empresa está satisfeita com seu desempenho em gerenciamento de projetos. Ademais, argumenta que um EP pode criar alguns problemas sem trazer os benefícios esperados. Portanto, pensa que não vale à pena criar um EP-TI.

\section{Características da cultura com relação a gerenciamento de projetos}

Não há uma metodologia padronizada para gerenciar projetos de TI. Embora planejamento e gerenciamento de projetos tenham considerável importância para o CIO, ter um método padrão para gerenciar projetos é considerado pouco importante e cada área é livre para gerenciar seus projetos da forma que achar mais conveniente. A empresa é muito bem-sucedida, as equipes são muito antigas, a rotatividade em nível executivo é muito baixa. Todos sabem exatamente o que fazer e como fazer, porque vêm fazendo o mesmo trabalho há bastante tempo. A memória da empresa está nas pessoas e é muito forte. Isso diminui a percepção de que há necessidade de formalização de métodos de trabalho. Na visão dos executivos, seria melhor que os métodos estivessem documentados, mas o resultado poderia ser uma documentação imensa, que talvez não fosse lida e consultada. Embora o número de projetos em andamento na empresa seja extraordinariamente maior do que na empresa com EP-TI, a empresa sem EP-TI não faz acompanhamento rotineiro de algumas estatísticas usuais sobre 0 desempenho no gerenciamento de projetos. Percebe-se que a empresa privilegia a flexibilidade e a ação à formalização.

Existe alguma estruturação nos processos para gestão dos projetos e da carteira de projetos. As diversas áreas de TI têm os seus processos de controle, mas não existe padrão de uma área para outra (por exemplo, status report) e há pouco formalismo. Entretanto, não se sente falta de mais padrão e mais formalização e considera-se que todos os projetos são controlados adequadamente (custo atual, custo no final, prazo de conclusão, atas de reunião, planos de ação). $\mathrm{O}$ acompanhamento dos principais projetos de TI é feito por diversos comitês que reúnem executivos de TI e das áreas de negócios. Nestas reuniões, os setores de TI responsáveis pela execução de um projeto relatam a situação de andamento do projeto e são tomadas decisões importantes para a vida do projeto.

Cabe ressaltar, porém, que não se consegue juntar as informações sobre todos os projetos facilmente. Em nível de diretoria, não existe controle estruturado. O CIO não tem uma visão única de todos os projetos em andamento, nem existem métricas de acompanhamento da carteira, mas ele recebe relatórios do andamento dos projetos, ainda que em diferentes formatos. Como não existe um setor que crie uma visão consolidada da situação da carteira de projetos da empresa, essa visão pode ser obtida através da soma de informações de cada setor, mas não haveria um padrão único para apresentação dessa visão. Por exemplo, não existem relatórios periódicos sobre a 
quantidade de projetos em andamento e sua situação em termos de aderência a prazos e custos. Acha-se que isto é importante, e deve-se caminhar para isso, mas não é crítico, ou seja, não ter esta visão consolidada não causa problemas. Cumpre notar que o CIO não sente falta desse relatório consolidado porque ele interage diariamente com os responsáveis dos diversos setores e é informado dos problemas nos projetos. Ademais, os investimentos são aprovados pelo CIO, o que lhe permite acompanhar mais de perto a situação dos projetos. Essa situação é satisfatória, e ele não sente necessidade de mudança.

Não obstante, há consciência de que sem um gerenciamento efetivo pode ocorrer de se descobrir tarde demais a existência de problemas de qualidade e atrasos nos projetos. Acima de tudo, porém, busca-se resultado, e não planejamento como um fim em si mesmo. As melhores práticas, por exemplo, são adotadas somente se houver percepção de que trarão resultados, mas não como um fim em si mesmo.

\section{Desenvolvimento da competência em gerenciamento de projetos}

Conforme visto, não existe um padrão organizacional para a condução de projetos, nem existe uma metodologia usada uniformemente por todas as áreas de TI da empresa. Cada área e equipe têm autonomia para decidir a forma de conduzir os projetos. Por exemplo, uma das áreas de TI (suporte a desenvolvimento de sistemas) elaborou uma metodologia para desenvolvimento de sistemas que contempla também um método para o gerenciamento de projetos baseado no PMI (2004a).

Existe, entretanto, um esforço de treinamento para toda a estrutura de TI nas técnicas e melhores práticas de gerenciamento de projetos, também conforme o modelo sugerido pelo PMI-(2004a). Este esforço é facilitado pelo setor de Governança de TI, que é staff do CIO. Este setor estuda as melhores práticas e modelos de referência para TI existentes no mercado. Estuda ainda as práticas e processos adotados nas áreas de TI, para então discutir com as áreas sugestões de melhoria em seus controles e processos internos.

Os processos de desenvolvimento de sistemas e gerenciamento de projetos também são objeto deste esforço do setor Governança de TI. Há um grupo dentro de Governança de TI que vêm se dedicando à melhoria dos processos de gestão de projetos, tanto para TI como também para áreas de negócios, por exemplo, marketing. Este grupo fez uma avaliação dos processos de gerenciamento de projetos usados tanto nas áreas de desenvolvimento de sistemas como nas áreas de infra-estrutura. A conclusão é que na maioria das áreas existe oportunidades de melhoria, pois não existem padrões formalizados para a execução e monitoramento dos processos de gerenciamento de projetos. Os processos conseguem ser repetidos por cada área, mas cada área tem seus próprios processos. Após análise dos processos de gerenciamento de projetos de cada área, melhorias são sugeridas, novos processos são definidos, documentados, publicados e implementados em um sistema corporativo de apoio ao gerenciamento de projetos.

Cada uma das áreas de TI está sendo analisada com esta finalidade e existia um plano definindo as áreas que seriam avaliadas em 2007. Algumas áreas da empresa olham este esforço de forma positiva, achando isto muito importante, enquanto outras olham com ceticismo. Existem dúvidas se a criação de etapas, documentos de controle, atividades padronizadas, etc., realmente conduza a melhores resultados. Teme-se que a criação de metodologia crie burocracia sem trazer resultados. Algumas áreas de 
desenvolvimento de sistemas escolheram atuar na melhoria das suas competências em gerenciamento de projetos, enquanto outras escolheram outros temas como mais prioritários, por exemplo, levantamento de requisitos ou realização de testes em sistemas. As áreas têm autonomia para tomar esta decisão.

Portanto, a área de Governança desempenha uma função típica de EP, pois desenvolve as competências da empresa em gerenciamento de projetos. Inclusive, pode dar apoio à criação de EP dentro das áreas, caso elas tenham interesse nisso. Porém, o responsável pela área de Governança não se considera um EP-TI, pois não acompanha projetos das áreas, restringindo-se apenas a dar suporte em adequações eventualmente necessárias na metodologia de gerenciamento adotada. Cabe notar que essa percepção é consistente com a definição de EP adotada neste trabalho. Como a área não coordena nem monitora o gerenciamento dos projetos de TI, ela não pode ser considerada um EPTI. Cabe notar que embora não exista EP-TI nas áreas analisadas, está sendo considerada a possibilidade de criar um EP dentro da diretoria de infra-estrutura. Se existisse, se esperaria uma melhoria nos resultados dos projetos, com mais aderência a custos e prazos.

Com relação às demais funções tipicamente exercidas pelo EP-TI, notou-se que elas estão distribuídas entre vários setores de TI, tendo-se constatado que a satisfação com os resultados no desempenho destas funções varia de razoável a muita.

\section{Razões para não criar um EP-TI}

O Quadro 4 apresenta as razões da empresa para a decisão de não criar um EP-TI. Adotou-se como referência a lista de razões sugerida por Englund, Grahan e Dinsmore (2003, p. 50). Em uma escala de importância que vai de (1) = nenhuma a (5) = muita, passando por pouca, razoável e considerável, nota-se que há duas razões com importância considerável - o EP estimula a burocracia e o EP aumenta o custo fixo, e pode não valer a pena - e duas com importância razoável - o EP não apresenta evidências concretas de que aumenta o sucesso dos projetos e o EP pode desviar a atenção da entrega dos projetos. Cabe notar que entre as demais razões listadas (9), a maioria (7) foi considerada de nenhuma importância.

\begin{tabular}{l|c|l}
\hline \multicolumn{1}{c|}{ Razão } & $\begin{array}{c}\text { Importância } \\
\text { da razão }\end{array}$ & \multicolumn{1}{|c}{ Observações dos entrevistados } \\
\hline $\begin{array}{l}\text { Não há evidências concretas de que } \\
\text { aumenta o sucesso dos projetos }\end{array}$ & 3,3 & $\begin{array}{l}\text { Não está claro o quanto vai ficar } \\
\text { melhor e entregar mais por conta } \\
\text { desta estrutura }\end{array}$ \\
\hline $\begin{array}{l}\text { Concentra o poder em partes da } \\
\text { organização }\end{array}$ & 2,3 & $\begin{array}{l}\text { Pode criar um filtro, em algumas } \\
\text { empresas }\end{array}$ \\
\hline $\begin{array}{l}\text { Atrapalha a iniciativa dos gerentes de } \\
\text { projeto }\end{array}$ & 1,3 & -- \\
\hline
\end{tabular}




\begin{tabular}{|c|c|c|}
\hline Razão & $\begin{array}{l}\text { Importância } \\
\text { da razão }\end{array}$ & Observações dos entrevistados \\
\hline $\begin{array}{l}\text { Aumenta o custo fixo, e pode não } \\
\text { valer à pena }\end{array}$ & 3,7 & $\begin{array}{l}\text { Há mais gente gerenciando do que } \\
\text { entregando projeto }\end{array}$ \\
\hline Estimula a burocracia & 4,3 & -- \\
\hline $\begin{array}{l}\text { Torna a responsabilidade dos gerentes } \\
\text { de projetos mais difusa }\end{array}$ & 1 & -- \\
\hline $\begin{array}{l}\text { Dilui a capacidade dos gerentes de } \\
\text { projetos de dirigir atividades }\end{array}$ & 1 & -- \\
\hline $\begin{array}{l}\text { Afasta bons profissionais do } \\
\text { gerenciamento de projetos }\end{array}$ & 1 & -- \\
\hline $\begin{array}{l}\text { Pode multiplicar erros se não estiver } \\
\text { na direção certa }\end{array}$ & 1 & -- \\
\hline $\begin{array}{l}\text { Pode desviar a atenção da entrega de } \\
\text { projetos }\end{array}$ & 3 & $\begin{array}{l}\text { A forma passa a ser mais } \\
\text { importante do que o conteúdo }\end{array}$ \\
\hline $\begin{array}{l}\text { Tende a ser dirigido por processos, e } \\
\text { não por projetos }\end{array}$ & 1,3 & -- \\
\hline $\begin{array}{l}\text { Cria ressentimento entre os gerentes } \\
\text { de projeto }\end{array}$ & 1 & -- \\
\hline $\begin{array}{l}\text { Estimula lutas de poderes dentro da } \\
\text { organização }\end{array}$ & 2 & $\begin{array}{l}\text { Alguém passa a dar palpite para } \\
\text { uma área que pode não querer } \\
\text { palpites }\end{array}$ \\
\hline
\end{tabular}

Quadro 4: Razões para a decisão de não criar um EP-TI na empresa sem EP-TI.

Os dados acima podem ser mais bem compreendidos se interpretados com a opinião da direção sobre o desempenho atual do gerenciamento de projetos na empresa. O grau de satisfação de executivos sobre o andamento dos projetos (custo e prazo) e o controle da carteira é considerável, muito embora as expectativas da direção sejam cada vez maiores, e muito embora tenham existido no passado contextos organizacionais em que completar projetos com sucesso foi muito importante. Por exemplo, houve períodos de transformação organizacional, de crescimento, ou de reestruturação, em que empresas concorrentes foram adquiridas e integradas à empresa, novas áreas de negócio e novos produtos foram lançados, etc. Acredita-se que as áreas da empresa são muito competentes e grandes desafios podem ser vencidos graças a isso. Não existe nenhuma queixa no grupo executivo com relação tanto a resultados de projetos (custo, prazo e qualidade) como em relação ao processo de controle do portfolio, exceto o reconhecimento de que atualmente a obtenção de informações sobre a situação de 
projetos depende muitas vezes de relacionamento pessoal, não existindo uma forma mais automática e impessoal de obter estas informações.

Similarmente, a satisfação com as práticas de gerenciamento de projetos da empresa também é considerável, apesar de não existir metodologia padronizada para gerenciar os projetos. Conforme já descrito, não existe uma metodologia padrão, mas dentro da metodologia de desenvolvimento de sistemas há uma referência a gerenciamento de projetos. O trabalho sendo executado pela área de Governança de TI para aprimoramento de competências organizacionais em gerenciamento de projetos e controle dos projetos visa um desejável aprimoramento dessas competências, mas não é visto como crítico para a implementação de planos estratégicos. Acredita-se que a satisfação com as práticas de gerenciamento de projetos da empresa aumentará quando o trabalho executado por Governança de TI tiver permeado toda a área de TI. Cabe ressaltar que a direção de TI não elimina a possibilidade de criação de um EP-TI no futuro. No momento, porém, não existem planos de fazer isso em curto prazo.

Abaixo são sintetizados os motivadores para a decisão de não criar um EP-TI conforme opinião dos três entrevistados, com reprodução das passagens das entrevistas que evidenciam a presença destes motivadores:

a) Satisfação com o desempenho em gerenciamento de projetos e o controle do portfolio;

- Pesquisador: “A idéia do PMO, ela já foi considerada? Se já foi considerada, que razões justificaram a não criação?”. Responsável Governança de TI: “ ...[a empresa] ao longo do tempo foi criando equipes bastante capacitadas para atuar nas áreas, nas diversas áreas, entre desenvolvimento de sistemas, tecnologia, e [a empresa] tem sido muito bem sucedida ao longo do tempo, nas iniciativas dela, então isso também cria uma certa resistência a você estar introduzindo mudanças

- Pesquisador: “...a grande missão do escritório de projetos seria...melhorar a entrega dos projetos.......se a empresa, ela está tendo problemas com essas entregas, se os projetos estão indo mal, isso vai ser um motivador, agora, se vocês estão felizes...”. Responsável Desenv. Sistemas: “...é considerável o grau de satisfação com o andamento dos projetos, é considerável...nós não estamos sendo pressionados por uma área de negócios, "vocês precisam melhorar!’, nós não estamos sendo cobrados assim.” Responsável Infraestrutura: "O controle da carteira [a satisfação] é considerável hoje...Quanto a prazo, o grupo executivo, ninguém está se ressentindo disso, de ter esse acompanhamento.”

b) Um EP estimula a burocracia, aumenta o custo fixo e pode desviar a atenção da entrega dos projetos;

- Pesquisador: "Essa informalidade [na metodologia], vocês consideram como positivo porque dá flexibilidade, agilidade, não se perde tempo com burocracia? ”. Responsável Governança de TI: “...quando você começa a criar...muitos documentos, muito formalismo, você aumenta muito a burocracia e existe muita dúvida de quanto vale a pena... o que você tem de benefício com isso?... se você consegue ganhar alguma coisa no final da 
linha, não é muito claro...”

- Pesquisador: “ [concordam que um PMO] aumenta o custo fixo, pode não valer à pena, estimula a burocracia, [distrair da entrega dos projetos]...?” Responsável Desenv. Sistemas: "Esse começa a ser perigoso, tem mais gente gerenciando do que fazendo gol...pode distrair da entrega de projetos, eu acho que isso também é um risco, porque você começa a olhar tanto o meio, é tão mais importante a forma do que o conteúdo.” Responsável Infra-estrutura: “ Acho que aqui pode sim, aí pode ser...”

- Pesquisador: “...projetos críticos ou estratégicos... entende-se que o PMO pode ajudar dando visibilidade, enfim, alertando essa carteira...”. Responsável Desenv. Sistemas: "O acompanhamento do PMO [de empresa adquirida]... o que o pessoal tem feito lá, os PMOs que eram [da empresa adquirida] e estão fazendo com a gente, super ajuda, é uma ajuda, é fantástico, a pergunta é assim, aquele custo vale para todo o tamanho? É a estória do molho ficar mais caro do que o frango.” Responsável Infraestrutura: "Exatamente...tem o pessoal do PMO que gerencia o gerente..."

- Pesquisador: “[O PMO] estimula a burocracia?”. Responsável Infraestrutura:” ...isso é verdade, isso eu acho...”. Responsável Desenv. Sistemas: "Também estimula."

c) Não há evidências concretas de que aumenta o sucesso dos projetos ${ }^{1}$.

Pesquisador: “A idéia do PMO, ela já foi considerada? Se já foi considerada, que razões justificaram a não criação?”. Responsável Governança de TI: “... No fundo aqui eu acho que é assim, as principais coisas aqui não é muito claro o quanto você vai ficar melhor e vai entregar mais por conta de ter essa estrutura...”

Pesquisador: "[O PMO] agrega mais valor do que custo, essa é a pergunta.” Responsável Desenv. Sistemas: "É verdade, mas na verdade, eu acho que está equilibrando, no caso da [empresa adquirida]...tinha muito PMO e ele fazia muito mais o papel de compliance do que o papel realmente...realmente, de delivery, de entrega ... então ... quando a gente comparava com a nossa empresa [sem PMO], aqui era muito mais efetiva.”

\section{DISCUSSÃO}

O estudo de caso da empresa com EP-TI permitiu identificar dois motivadores para a decisão de criação de EP: insatisfação com a metodologia de gerenciamento de projetos no referente ao estabelecimento de requisitos e insatisfação com a capacidade de TI de entregar projetos dentro do prazo, custo e com a qualidade esperada. $\mathrm{Na}$ literatura, diversos autores fazem referência a estes motivadores. De fato, o motivador ‘aperfeiçoar o gerenciamento de projetos e reduzir o número de projetos problemáticos’

\footnotetext{
${ }^{1}$ Cabe notar que houve divergências entre os executivos: 2 acreditam que não aumenta, e 1 acredita que aumenta.
} 
relacionado no Quadro 1 é uma síntese adequada desses dois motivadores encontrados no estudo de caso.

Observou-se ainda que a criação formal do EP-TI é fruto de um processo que durou anos e teve alguns estágios. Em 2000, houve uma tentativa mal-sucedida de criar um EP-TI. Em 2003, foi formalmente atribuído a alguns analistas de sistemas o papel de gerentes de projetos. Em 2005, foi criado um setor focado em gerenciamento de projetos de TI, que pode ser considerado um EP-TI. Ainda nesse ano, um EP nível 1 (dedicado a um único projeto) foi criado para dar suporte ao planejamento e controle de um projeto grande e estratégico de TI. Finalmente, em 2007, foi criado outro EP-TI, chamado de PMO. Graças à melhoria observada nos indicadores de sucesso em gerenciamento de projetos, consolidou-se na empresa a opinião de que vale a pena ter um setor com pessoas dedicadas exclusivamente ao gerenciamento de projetos em TI. Ademais, superou-se a resistência da direção da empresa à idéia de criar um segundo EP-TI. Assim, observou-se que a criação de um EP-TI não é necessariamente um evento pontual dentro da vida da empresa, mas pode ser o fruto de um lento processo de amadurecimento. Na revisão de literatura não encontramos nenhum insight a esse respeito.

O estudo de caso da empresa sem EP-TI, por outro lado, indicou a existência de três motivadores para a percepção de que não é preciso criar um EP-TI. Primeiro, há satisfação com o desempenho em gerenciamento de projetos e o controle do portfolio. Segundo, acredita-se que a entidade pode ser prejudicial à empresa em alguns aspectos. E terceiro, há ceticismo com relação aos benefícios que um EP-TI pode proporcionar. Estas razões estão presentes na literatura, mas muitas outras razões para não criar um EP, encontradas na literatura, não foram consideradas relevantes pelos entrevistados nessa empresa. Será necessário mais pesquisa para confirmar se algumas dessas razões são realmente válidas ou não.

Observou-se ainda que a cultura da empresa não valoriza o formalismo nos planos e nos processos. Esta característica, uma vez unida à opinião da direção de que um EP aumenta o formalismo - considerado burocracia -, também ajuda explicar porque a idéia do EP-TI não prospera na empresa. Logo, é lícito afirmar que a opinião dos executivos sobre um EP é uma variável interveniente importante para explicar a decisão sobre a criação ou não da entidade. Essa opinião poderia ser considerada uma síntese dos motivadores apresentados no Quadro 2, o que permitiria reduzir a lista de motivadores da decisão de criação de EP citados na literatura, sem contudo perder informação. Cabe destacar que não foi encontrada na literatura menção à importância da cultura como direcionador da decisão de criação de um EP-TI.

Finalmente, notou-se que as funções normalmente desempenhadas pelo EP estão distribuídas entre diversos setores, existindo satisfação com o desempenho da empresa nestas funções.

\section{LIMITAÇÕES E PESQUISA FUTURA}

A principal limitação dessa pesquisa diz respeito ao uso de apenas dois casos. Possivelmente em função disso, foi possível confirmar apenas parcialmente os motivadores para a tomada de decisão de criação de EP-TI mencionados na literatura. 
Mais estudos de casos -- tanto de empresas que criaram EP-TI como de empresas que analisaram essa possibilidade, mas decidiram não criar um EP-TI -- são necessários para confirmar e talvez enriquecer os motivadores indicados pela literatura.

Sugerimos como pesquisa futura a ampliação deste estudo exploratório e qualitativo através da realização de mais estudos de casos, tanto de empresas que tem como de empresas que não tem EP-TI. O objetivo dessa pesquisa seria desenvolver um modelo conceitual das razões que levam as empresas a criar um EP-TI. Este modelo seria baseado tanto em teoria existente como em evidências encontradas durante a realização dos estudos de caso. Mais à frente, em uma pesquisa futura sucessiva, sugerese a realização de uma pesquisa quantitativa ampla com dois objetivos. O primeiro seria testar a validade do modelo conceitual desenvolvido anteriormente. O segundo, construir uma regra discriminante que permitisse diferenciar o contexto de empresas que têm EP-TI das empresas que não têm. Sugerimos que nestas pesquisas futuras seja mantido o foco em grandes empresas nacionais, privadas, não orientadas a projetos.

Outra sugestão de pesquisa futura emerge da observação de que houve uma melhora substancial no sucesso no gerenciamento de projetos após a criação do papel do gerente de projetos em tempo integral. Ademais, a metodologia de gerenciamento de projetos teve grande adesão por parte dos gerentes de projetos porque essa metodologia foi elaborada pelos próprios gerentes de projeto. Estes pontos nos parecem muito importantes e sugerem um aprofundamento em pesquisas futuras, pois podem indicar ações muito eficazes para empresas que objetivam melhorar o sucesso em gerenciamento de projetos.

\section{CONSIDERAÇÕES FINAIS}

Este artigo apresenta dois estudos de caso sobre os direcionadores da decisão de criar ou não criar Escritórios de Projetos na área de TI (EP-TI). Através da análise do contexto de duas empresas com relação ao gerenciamento de projetos de TI, uma com e uma sem EP-TI, foi possível obter três resultados importantes do ponto de vista de contribuição acadêmica. Primeiro, foram confirmados alguns dos motivadores da decisão de criar e não criar um EP-TI mencionados na literatura. Isso é importante porque os motivadores mencionados na literatura carecem de sustentação empírica mais adequada. Portanto, esse artigo estabelece bases mais sólidas para a realização de pesquisa futura. Segundo, foram obtidos insights importantes sobre o fenômeno de criação de EP-TI. Observou-se que a cultura das empresas é um direcionador influente, muito embora esta variável não seja mencionada na literatura pesquisada. Ademais, foi possível constatar que a criação de um EP-TI não é necessariamente um evento, mas pode ser o fruto de um longo processo de amadurecimento. A literatura pesquisada também não menciona esta possibilidade, que cria a percepção de que há muitos caminhos à disposição das empresas na criação de EP-TI. Esses insights contribuem para um entendimento mais aprofundado do fenômeno de criação de EP-TI e permitem dar um direcionamento mais adequado a pesquisas futuras sobre o tema. Finalmente, o terceiro resultado importante apresentado neste artigo encontra-se nas sugestões de pesquisa futura.

Acredita-se ser de grande relevância a indicação de pesquisa futura visando a elaboração e teste de um modelo conceitual dos direcionadores da decisão de criação de um EP-TI. Imagina-se que esta pesquisa futura poderá trazer importante contribuição 
tanto para a teoria como para a prática do gerenciamento de projetos nas empresas.

\section{REFERÊNCIAS}

Aubry, M., Hobbs, B., \& Thuillier, D. (2007, Maio). A new framework for understanding organisational project management through the PMO. International Journal of Project Management, 25(4), 328-336.

Baccarini, D. (1999, December). The logical framework method for defining project success. Project Management Journal, 30(4), 25-32.

Bernstein, S. (2000, December). Project Offices in Practice. Project Management Journal, 31(4), 4-6.

Block, T., \& Frame, J. (1998). The project Office. Menlo Park: Crisp Learning.

Cleland, D. I., \& Ireland, L. R. (2007). Project Management: Strategic Design and Implementation (5a Ed.). Singapore: McGraw-Hill.

Crawford, J. K. (2002). The Strategic Project Office. Boca Raton: Taylor \& Francis.

Dai, C. X., \& Wells, W. G. (2004, Outubro). An Exploration of Project Management Office Features and their Relationship to Project Performance. International Journal of Project Management, 22(7), 523-532.

Desouza, K. C., \& Evaristo, J. R. (2006, Outubro). Project Management Offices: A case of knowledge-based archetypes. International Journal of Information Management, 26 (5), 414-423.

Dubè, L., \& Parè, G. (2003, Dezembro). Rigor in Information Systems Positivist Case Research: Current Practices, Trends and Recommendations. MIS Quarterly, 27(4), 597635.

Eisenhardt, K. M. (1989, Outubro). Building Theories from Case Study Research. Academy of Management Review, 14(4), 532-550.

Englund, R. L., Graham, R. J., \& Dinsmore, P. C. (2003). Creating the Project Office A Manager's Guide to Leading Organizational Change. San Francisco: Jossey-Bass.

Hobbs, B., \& Aubry, M. (2007, Março). A Multi-Phase Research Program Investigating Project Management Offices (EP): The Results of Phase 1. Project Management Journal, 38(1), 74-86.

IT GOVERNANCE INSTITUTE. Cobit 4.0: Control Objectives, Management Guidelines, Maturity Models. Rolling Meadows, 2005.

Jiang, J. J., Klein, G., \& Pick, R. A. (2003, Janeiro). The impact of IS department organizational environments upon project team performances. Information \& Management, 40(3), 213-220.

Judgev, K. (2004). Project Management as a Strategic Asset: what does it look like and how do organizations get there? In D. P. Slevin, D. L. Cleland, \& J. K. Pinto (Ed.). Innovations: Project Management Research 2004. (Chap. 10, pp.161-174). Newton 
Square: Project Management Institute.

Maximiano, A. C. A., \& Anselmo, J. L. (2006). Escritórios de Gerenciamento de Projetos: um estudo de caso. Revista de Administração da USP, 41(4), 394-403.

Milosevic, D., \& Patanakul, P. (2005, Abril). Standardized project management may increase development projects success. International Journal of Project Management, 23(3), 181-192.

Project Management Institute. (2004). A Guide to the Project Management Body of Knowledge (3rd ed.). Newton Square, PA: PMI.

Project Management Institute. (2004). Um Guia do Conjunto de Conhecimentos em Gerenciamento de Projetos Guia PMBOK (3rd ed.). Newton Square, PA: PMI.

Project Management Institute. (2004, 2005 e 2006). Seção Rio de Janeiro. Relatório do Estudo de Benchmarking de Gerenciamento de Projetos Brasil. Recuperado em 31 março, 2007, de http://www.pmirio.org.br/

Rad, P. (2001). Is your organization a candidate for Project Management Office (PMO)? AACE International Transactions, p. PM.07.1-PM.07.4

Trochim, W. M. K., \& Donnelly, J. P. (2007). The research methods knowledge base (3rd ed.). Mason, $\mathrm{OH}$ : Thomson.

Verzuh, E. (2000). MBA Compacto: Gestão de Projetos (5a Ed.). Rio de Janeiro: Campus. 
436 Spelta, A.G., Albertin, A. L. 